\title{
Os desafios e as ameaças na investigação em desporto de rendimento
}

\section{The challenges and threats researching sports performance}

Tiago M. Barbosa ${ }^{1 *}$

EDITORIAL | EDITORIAL

No mais recente editorial foi abordada a questão dos critérios para levar manuscritos a revisão externa pelos pares, de acordo com a política editorial da Motricidade. A certa altura exemplifica-se esta questão com a submissão de artigos nas áreas da saúde, da aptidão ou exercício físico. Com efeito, uma percentagem significativa dos trabalhos submetidos a esta revista enquadra-se nestes domínios.

Neste momento, a segunda área com maior número de submissões é o rendimento desportivo. É sobre os trabalhos nesta área temática que gostaríamos de nos dedicar agora, apresentando algumas sugestões aos potenciais autores.

A primeira ameaça a um trabalho neste domínio começa desde logo pelo recrutamento dos sujeitos. Estamos conscientes que quanto mais elevado o nível competitivo, mais difícil será o recrutamento de um número alargado de participantes. Ainda assim, tanto quanto possível os autores devem apresentar uma justificação para o tamanho amostral e idealmente a descrição da potência da amostra.

No reverso da medalha, o recrutamento de atletas com menor expressão competitiva deve levar os autores a terem algum cuidado na extrapolação dos seus resultados e conclusões para atletas de melhor nível competitivo. O processo de induzir um resultado de uma amostra de praticantes de baixo nível competitivo para a população de atletas de elite (e vice-versa), nem sempre será uma premissa verdadeira. Pese embora, há que admitir, seja mais fácil o recrutamento de um elevado número de sujeitos e corresponder aos requisitos necessários para uma adequada potência da amostra.

No domínio do desporto de rendimento, as principais questões de interesse hoje em dia relacionam-se com o efeito dose-resposta. Portanto, os autores são convidados a reportar com detalhe as cargas de treino, o processo de planeamento e periodização. Sabe-se que nem todos os treinadores e atletas estão disponíveis para partilhar estes detalhes. Contudo, um cabal entendimento do rendimento do atleta depende de cargas internas e externas de treino que lhe são sujeitas.

Ainda neste particular, no caso de desenhos experimentais do tipo longitudinal, notavelmente programas de intervenção, será requisito a inclusão de pelo menos um grupo de controlo. Provavelmente um desenho experimental ótimo reportará um ou dois grupos experimentais com programas de intervenção distintos mais um grupo de controlo. Os ensaios clínicos duplo-cego randomizados (double-blind randomized controlled trials) são tidos como os desenhos experimentais ideais para este tipo de problemas, mas infelizmente nem sempre exequível.

Relativamente a análise de dados. A nossa experiencia dita que em primeiro lugar as variações ou diferenças entre sujeitos de nível competitivo próximo (estudos transversais) ou mudanças ao longo do tempo (estudos longitudinais) tendem a ser mínimas. As clássicas estatísticas de teste de hipótese nula

\footnotetext{
${ }^{1}$ Editor Chefe da Revista Motricidade; Physical Education \& Sports Science Academic Group, National Institute of Education, Nanyang Technological University

*Autor Correspondente: NIE5-03-31, 1 Nanyang Walk, Singapore, Email: editor.in.chief@revistamotricidade.com
} 


\section{2 | TM Barbosa}

nem sempre são suficientemente sensíveis a estes fenómenos tão característicos do desporto de rendimento. Portanto, será desejável que sejam complementadas com análises suplementares, como por exemplo análise dos tamanhos dos efeitos (particularmente se a dimensão da amostra não corresponde aos requisitos da sua potência, determinada previamente). Também pode ser necessário o controlo de fatores de confusão (confounding factors). Especialmente em estudos levados a cabo em contexto real, no terreno, torna-se mais difícil o controlo de todos os potenciais fatores de confusão e contaminação dos resultados. Portanto, isto pode ser realizado a posteriori através da seleção das estatísticas adequadas.

Em determinadas circunstâncias porque a dimensão amostral não será elevada, pode considerar-se a aplicação de técnicas de reamostragem dos dados. Ainda nestes casos de amostras limitadas, análises mais individualizadas podem ser particularmente uteis, existindo para o efeito também procedimentos estatísticos que nos conferem uma visão casuística (i.e. estudo de caso ou individualizada) dentro de uma análise mais global de toda a amostra.

Noutros domínios científicos o outlier é considerado um desvio a norma, que se deve de evitar. Contudo, no desporto de rendimento e muito particularmente no desporto de elite o outlier tende a ser o atleta mais dotado. Mais do que criar estratégias para o eliminar da amostra e do estudo, os autores são encorajados a, se for esse o caso, efetuarem uma análise detalhada deste sujeito e das diferenças que possam existir relativamente a restante amostra. 